\title{
ANALYZING THE IMPACT OF STATINS USE IN TYPE 2 DIABETES MELLITUS PATIENTS AT A TERTIARY CARE HOSPITAL IN ANDHRA PRADESH
}

\author{
PANCHUMARTHI DIVYA JYOTHI ${ }^{1}$, PONNADA SRI DURGA ${ }^{2 *}$, YERUVA VEENA $^{2}$, SHAIK AFSARI ${ }^{2}$
}

${ }^{1}$ Department of Pharmacy Practice, Nirmala College of Pharmacy, Guntur, Andhra Pradesh, India. ${ }^{2}$ Department of Nirmala College of Pharmacy, Guntur, Andhra Pradesh, India. Email: rosydurga96@gmail.com

Received: 10 April 2020, Revised and Accepted: 01 June 2020

\section{ABSTRACT}

Objectives: The objectives of the study were to analyze the impact of statins uses in Type-2 diabetes mellitus patients at a tertiary hospital.

Methods: It is a hospital-based prospective and observational study. The study was conducted in the General Medicine Department of Manipal Super Speciality Hospital, Vijayawada, Andhra Pradesh, India. Six months (August 2018-January 2019), 450 cases were collected from the general medicine department.

Results: A total of 450 patients data were collected, the results show that rosuvastatin at its list dose in this study (10 mg) was more effective at reducing fasting blood sugar (FBS), post-prandial blood sugar (PPBS), and hemoglobin A1C (HbA1c) levels than rosuvastatin combination. Moreover, significant increment of these levels (FBS, PPBS, and HbA1c) was observed with atorvastatin combination followed by atorvastatin (10 mg, 20 mg, and $40 \mathrm{mg}$ ) in both treatment group as well as a control group.

Conclusion: We concluded that there is a significant rise in blood glucose levels (both FBS and PPBS) and also HbA1c levels (glycated hemoglobin) due to the usage of statins for a longer duration. Statistical analysis was performed using the Pearson correlation coefficient method (SPSS 20. Version) and two-tailed analysis of variance. The results were represented as $\mathrm{Z}$ value (correlation coefficient) and $\mathrm{p}$-value.

Keywords: Type 2 diabetes mellitus, New-onset diabetic statins, Fasting blood sugar, Post-prandial blood sugar, Glycated hemoglobin, Cardiovascular disease.

(C) 2020 The Authors. Published by Innovare Academic Sciences Pvt Ltd. This is an open access article under the CC BY license (http://creativecommons. org/licenses/by/4. 0/) DOI: http://dx.doi.org/10.22159/ajpcr.2020.v13i8.37682

\section{INTRODUCTION}

Diabetes is a bunch of metabolic diseases characterized by inappropriate hyperglycemia ensuing from defects in internal secretion, internal secretion action, or both. Symptoms of acute hyperglycemia embody kidney disease, polydipsia, polyphagia, weight loss, blurred vision, fatigue, headache, and poor wound healing. Chronic hyperglycemia will cause harm and probably failure of various organs, together with the eyes, heart, kidneys, blood vessels, and nerves [1]. Statins are medicines which are reduced lipid levels. Although steroid alcohol is essential for traditional cell and body to operate, high levels of steroid alcohol will result in cardiovascular complications. Many styles of statins exist such as statin drug, Baycol, Lescol, lovastatin, mevastatin, pitavastatin, rosuvastatin, and lipid-lowering medication [2]. Statins inhibit an accelerator known as reductase that controls steroid alcohol production within the liver. The medicines really act to exchange the hydroxy methylglutaryl-coenzyme A that exists within the liver, thereby speed down the steroid alcohol production method. These receptors relocate to the liver cell membranes and bind to passing low-density lipoprotein (LDL) and very LDL. Many people who begin statin treatment do so to lower their cholesterol level to $<5 \mathrm{mmol} / \mathrm{l}$, or by $25-30 \%$ [3]. The relationship between statins and diabetes, some experimental studies support the hypothesis that statins might cause polygenic disease by neutering aldohexose. Physiological condition through each impaired hypoglycemic agent secretion, and diminished hypoglycemic agent sensitivity. Moreover, inhibition of isoprenoid biogenesis by statins has been involved in the down-regulation of glucose transporter 4 (GLUT4) in adipocytes. GLUT4 mediates hypoglycemic agents stirred up the uptake of aldohexose in skeletal muscles and adipocyte. Statin drug and lipid-lowering medicine are shown to decrease the expression of GLUT4 in adipocytes which can end in impaired aldohexose tolerance. Adiponectin is a hypoglycemic agent sensitizing and anti-inflammatory protein free from adipocytes. Rosuvastatin and lipid-lowering medicine are shown to decrease plasma adiponectin levels and hypoglycemic agent sensitivity, whereas lipid-lowering cure raised each. Mitochondrial dysfunction in beta cells, skeletal muscles, and adipocytes have been coupled with the pathological process of polygenic disease. Since statins area unit far-famed to cause mitochondrial dysfunction in skeletal muscles, it is plausible that a similar mechanism is additionally accountable for their diabetogenic result. In addition, medicationinduced myokymia and fatigue might impair exercise capability and worsen sarcopenia that is related to aldohexose intolerance and sort two polygenic diseases. Therefore, multiple mechanisms might result in impairment of glycemic control and risk of a non-obese diabetic with statins [4] link between diabetes and hypertension. When hypertension and diabetes co-exist, the effects of one disease tend to make the other worse. This makes for a deadly combination. Diabetes does three things that may increase blood pressure, decreasing the blood vessels' ability to stretch increasing the amount of fluid in the body. Changing the way the body manages insulin. Hypertension and diabetes generally co-exist because they share similar risk factors, including being overweight, following an unhealthy diet, and living an inactive lifestyle [5].

\section{METHODS}

Approval of the protocol by the institutional ethics committee (IEC) The protocol for the proposed study was submitted to the IEC of Nirmala College of Pharmacy, Mangalagiri, Guntur, Andhra Pradesh (AP), India. The protocol was approved by the IEC on 13 July 2018.

\section{Research design}

It is a hospital-based prospective and observational study. The study was conducted in the General Medicine Department of Manipal Super Specialty Hospital, Vijayawada, AP, India. Six months 
(August 2018-January 2019), 450 cases were collected from the general medicine department.

\section{Study criteria}

Inclusion criteria

The following criteria were included in the study:

- Patients of both sex who are willing to participate.

- Patients having diabetes mellitus (DM) along with other diseases.

- Patients above 25 years.

Exclusion criteria

The following criteria were excluded from the study:

- Patients who are unable or unwilling to participate.

- Children, pregnant, and lactating women.

Source of Data

- Patient case sheets.

- Treatment chart.

- Laboratory reports (fasting blood sugar [FBS], post-prandial blood sugar [PPBS], hemoglobin A1C [HBA1C], and lipid profile).

- Other relevant data sources.

Statistical analysis

Statistical analysis was performed using the Pearson correlation coefficient method (SPSS 20. Version) and two-tailed analysis of variance (ANOVA). The results were represented as $\mathrm{Z}$ value (correlation coefficient) and $\mathrm{p}$-value $(\mathrm{p}<0.5)$.

\section{RESULTS}

Table 1 and Fig. 1: This table shows the percentage of the diseased population in particular sex, of which $62.6 \%(n=94)$ were males and $37.3 \%(n=56)$ were females.

Table 2 and Fig. 2: This table shows the percentage of the diseased population in particular sex, of which $62.6 \%(n=94)$ were males and $37.3 \%(n=56)$ were females.

Table 3 and Fig. 3: This table shows the percentage of the diseased population in particular age groups of subjects above 10 years of age

Table 1: Gender-wise distribution of diabetes in the treatment group

\begin{tabular}{ll}
\hline Gender & Number (\%) \\
\hline Male & $190(63.3)$ \\
Female & $110(36.7)$ \\
\hline
\end{tabular}

Table 2: Gender-wise distribution of diabetes in the control group

\begin{tabular}{ll}
\hline Gender & Number (\%) \\
\hline Male & $94(62.6)$ \\
Female & $56(37.3)$ \\
\hline
\end{tabular}

Table 3: Age-wise distribution of diabetes in the treatment group

\begin{tabular}{ll}
\hline Age & Number (\%) \\
\hline $11-20$ & $2(0.06)$ \\
$21-30$ & $2(0.06)$ \\
$31-40$ & $35(12)$ \\
$41-50$ & $91(30.6)$ \\
$51-60$ & $94(31.3)$ \\
$61-70$ & $54(18.7)$ \\
$71-80$ & $17(5.6)$ \\
$81-90$ & $5(1.7)$ \\
\hline
\end{tabular}

among the 300 patients in which 51-60 years age group of patients are high in number, that is, $31.3 \%$ (94).

Table 4 and Fig. 4: This table shows the percentage of the diseased population in particular age groups of subjects above 10 years of age among the 300 patients in which 51-60 years age group of patients are high in number, that is, $31.3 \%(94)$.

Table 5 and Fig. 5: The graph explains the percentage of the type of statin used. Monotherapy and combination therapy show in which the most commonly used atorvastatin combination therapy 58.36\% ( $\mathrm{n}=178)$

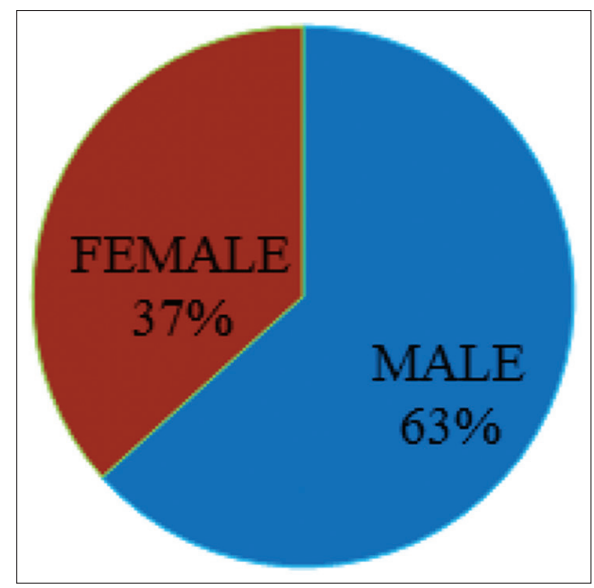

Fig. 1: Gender-wise distribution of diabetes in the treatment group

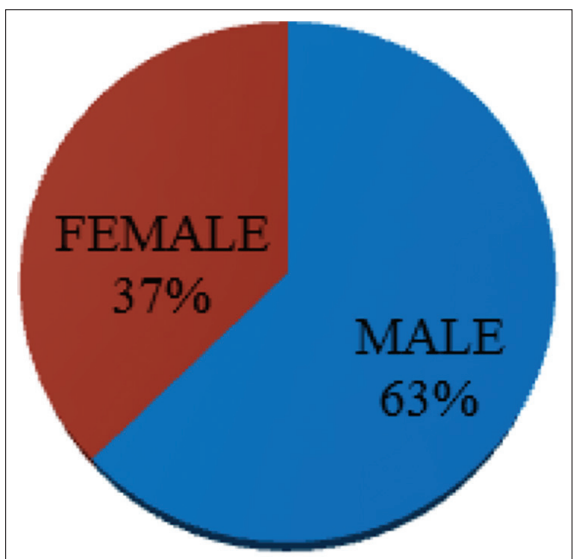

Fig. 2: Gender-wise distribution of diabetes in the control group

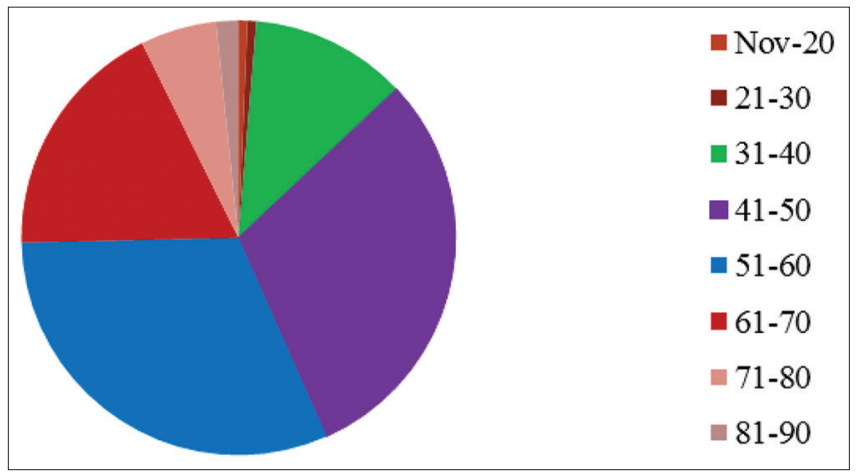

Fig. 3: Age-wise distribution of diabetes in the treatment group 
followed by atorvastatin (monotherapy) 26.9\% (n=82). Moreover, less widely used types are rosuvastatin combination therapy $4.59 \%(n=31)$ followed by rosuvastatin monotherapy $4.5 \%(n=14)$.

Table 6 and Fig. 6: The above table and graph explain about the percentage of the type of statin used. Both monotherapy and combination therapy shows in which the most commonly used kind of statin is atorvastatin combination therapy $54.6 \%(n=82)$ followed by atorvastatin.

Table 4: Age-wise distribution of diabetes in the control group

\begin{tabular}{ll}
\hline Age & Number (\%) \\
\hline $11-20$ & $2(0.06)$ \\
$21-30$ & $2(0.06)$ \\
$31-40$ & $35(12)$ \\
$41-50$ & $91(30.6)$ \\
$51-60$ & $94(31.3)$ \\
$61-70$ & $54(18.7)$ \\
$71-80$ & $17(5.6)$ \\
$81-90$ & $5(1.7)$ \\
\hline
\end{tabular}

Table 5: Types of statins used in the treatment group

\begin{tabular}{ll}
\hline Types of statins & Number (\%) \\
\hline Atorvastatin & $82(26.9)$ \\
Rosuvastatin & $14(4.59)$ \\
Atorvastatin+combination & $178(58.36)$ \\
Rosuvastatin+combination & $31(10.16)$ \\
\hline
\end{tabular}

Table 6: Types of statins used in treatment in the control group

\begin{tabular}{ll}
\hline Types of statins & Number (\%) \\
\hline Atorvastatin & $29(19.3)$ \\
Rosuvastatin & $11(7.3)$ \\
Atorvastatin+combination & $82(54.6)$ \\
Rosuvastatin+combination & $28(18.6)$ \\
\hline
\end{tabular}

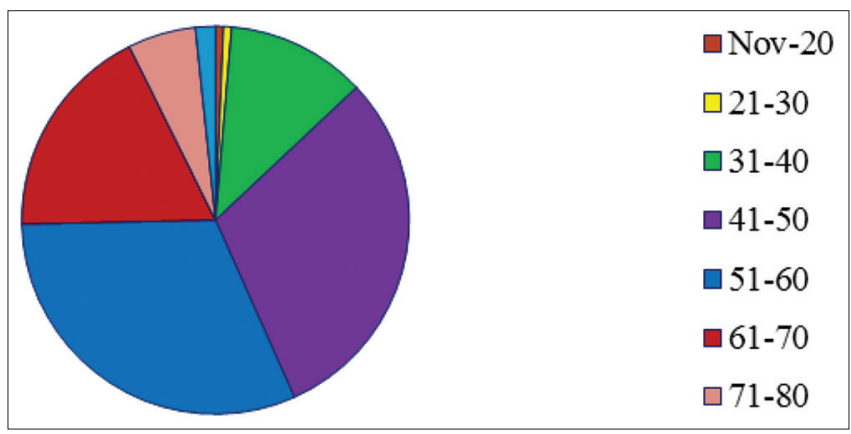

Fig. 4: Age-wise distribution of diabetes in the control group

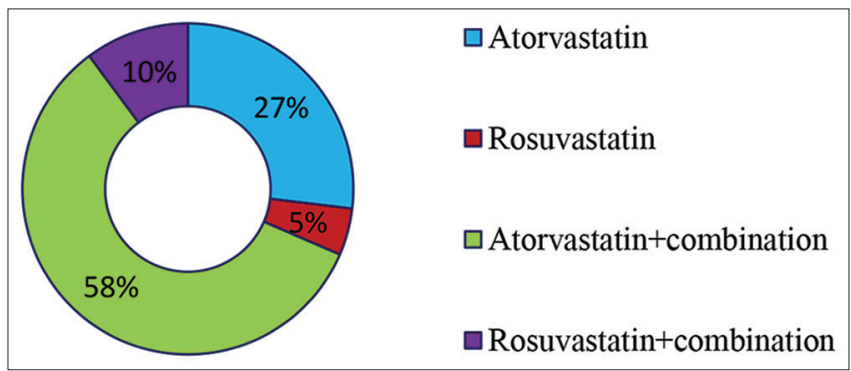

Fig. 5: Types of statins used in the treatment group
Table 7 and Fig. 7: It explains the percentage of fasting blood glucose levels, of which rosuvastatin monotherapy showed a remarkable decrease in FBS levels $(-17.9 \%)$ followed by rosuvastatin combination therapy $(-2.9 \%)$.

Table 8 and Fig. 8: It explains the percentage of post-prandial blood glucose levels, of which rosuvastatin monotherapy showed a remarkable decrease in FBS levels $(-28.9 \%)$ followed by rosuvastatin combination therapy $(-8.4 \%)$.

Table 9 and Fig. 9: It explains the percentage of HbA1c levels, of which rosuvastatin monotherapy showed a remarkable decrease
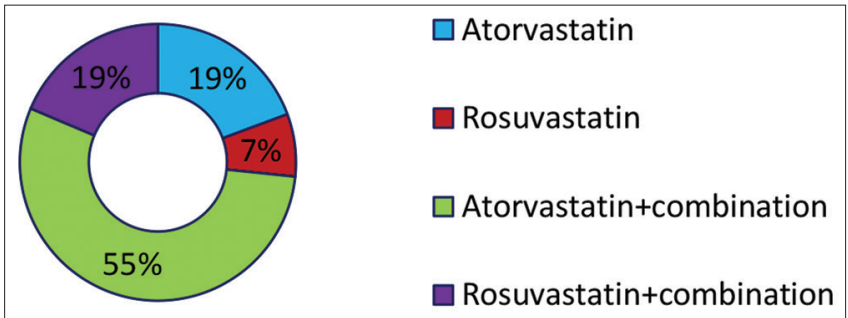

Fig. 6: Types of statins used in treatment in the control group

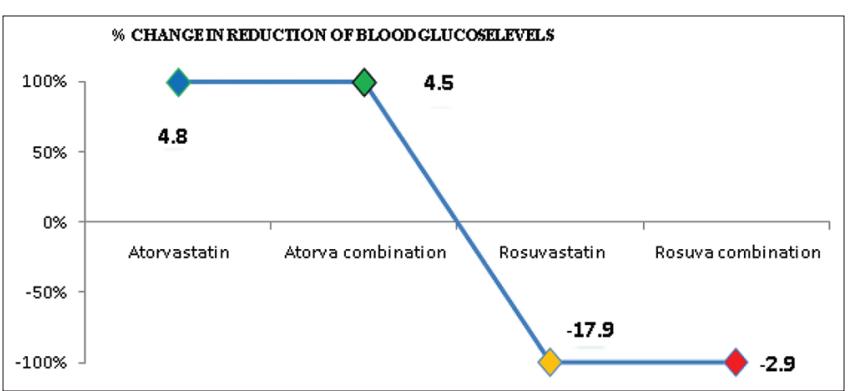

Fig. 7: Glucose levels (fasting blood sugar) of the treatment group

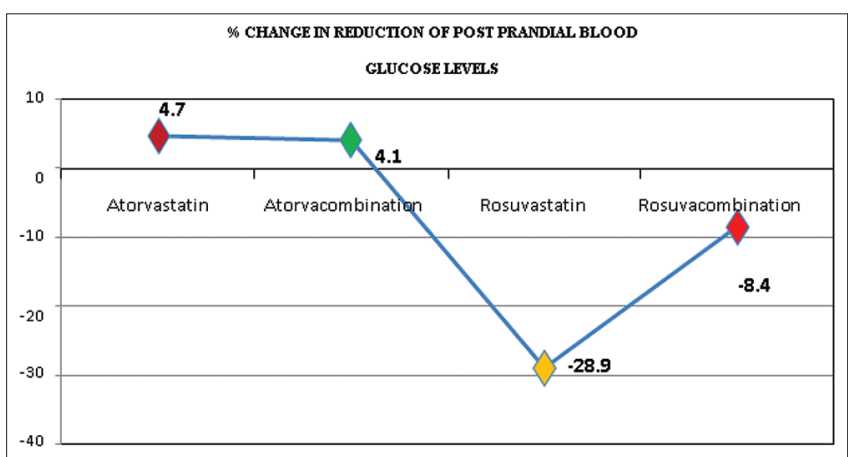

Fig. 8: Glucose levels (post-prandial blood sugar) of the treatment group

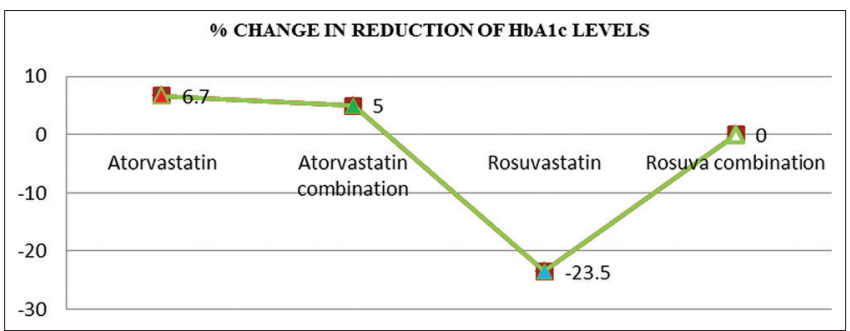

Fig. 9: Hemoglobin A1C levels of the treatment group 
in $\mathrm{HbA1c}$ levels $(-23.5 \%)$ followed by rosuvastatin combination therapy $(-1 \%)$.

Table 10 and Fig. 10: This table shows the percentage of fasting blood glucose levels, of which rosuvastatin monotherapy showed a remarkable decrease in FBS levels $(-22.2 \%)$ followed by rosuvastatin combination therapy $(-3.8 \%)$.
Table 11 and Fig. 11: It explains the percentage of post-prandial blood glucose levels, of which rosuvastatin monotherapy showed a remarkable decrease in FBS levels $(-21.6 \%)$ followed by rosuvastatin combination therapy $(-3.8 \%)$.

Table 12 and Fig. 12: It explains the percentage of HbA1c levels, of which rosuvastatin monotherapy showed a remarkable decrease

Table 7: Glucose levels (FBS) of the treatment group

\begin{tabular}{llll}
\hline Name of the statin & $\begin{array}{l}\text { Mean baseline blood glucose } \\
\text { level (mg/dl) }\end{array}$ & $\begin{array}{l}\text { Mean follow-up blood } \\
\text { glucose levels (mg/dl) }\end{array}$ & $\begin{array}{l}\text { Percentage (\%) change in the } \\
\text { reduction of blood glucose levels }\end{array}$ \\
\hline Atorvastatin & 145 & 152 & 4.8 \\
Atorvastatin combination & 153 & 160 & 4.5 \\
Rosuvastatin & 83 & 68 & -17.9 \\
Rosuva combination & 170 & 165 & -2.9 \\
\hline
\end{tabular}

FBS: Fasting blood sugar

Table 8: Glucose levels (PPBS) of the treatment group

\begin{tabular}{llll}
\hline Name of the statin & $\begin{array}{l}\text { Mean baseline post-prandial } \\
\text { blood glucose levels (mg/dl) }\end{array}$ & $\begin{array}{l}\text { Mean follow-up post-prandial } \\
\text { blood glucose levels (mg/d) }\end{array}$ & $\begin{array}{l}\text { Percentage (\%) change in reduction } \\
\text { of post-prandial blood glucose levels }\end{array}$ \\
\hline Atorvastatin & 209 & 219 & 4.7 \\
Atorvastatin combination & 218 & 227 & 4.1 \\
Rosuvastatin & 145 & 103 & -28.9 \\
Rosuva combination & 237 & 217 & -8.4 \\
\hline
\end{tabular}

PPBS: Post-prandial blood sugar

Table 9: HbA1c levels of the treatment group

\begin{tabular}{|c|c|c|c|}
\hline Name of the statin & $\begin{array}{l}\text { Mean baseline HbA1c } \\
\text { levels }(\mathrm{mg} / \mathrm{dl})\end{array}$ & $\begin{array}{l}\text { Mean follow-up HbA1c } \\
\text { levels (mg/dl) }\end{array}$ & $\begin{array}{l}\text { Percentage }(\%) \text { change in } \\
\text { reduction of } \mathrm{HbA1c} \text { levels }\end{array}$ \\
\hline & 7.4 & 7.9 & 6.7 \\
\hline Atorvastatin combination & 8.0 & 8.4 & 5 \\
\hline Rosuvastatin & 6.8 & 5.2 & -23.5 \\
\hline Rosuva combination & 8.1 & 8.1 & 0 \\
\hline
\end{tabular}

HbA1cl: Hemoglobin A1C

Table 10:FBS levels of the control group

\begin{tabular}{llll}
\hline Name of the statin & $\begin{array}{l}\text { Mean baseline blood } \\
\text { glucose levels (mg/d) }\end{array}$ & $\begin{array}{l}\text { Mean follow-up blood } \\
\text { glucose levels (mg/dl) }\end{array}$ & $\begin{array}{l}\text { Percentage (\%) change in } \\
\text { reduction of blood glucose levels }\end{array}$ \\
\hline Atorvastatin & 115 & 142 & 23.4 \\
Atorvastatin combination & 129 & 145 & 12.4 \\
Rosuvastatin & 90 & 70 & -22.2 \\
Rosuva combination & 129 & 124 & -3.8 \\
\hline
\end{tabular}

FBS: Fasting blood sugar

Table 11: PPBS levels of the control group

\begin{tabular}{llll}
\hline Name of the statin & $\begin{array}{l}\text { Mean baseline post-prandial } \\
\text { blood glucose levels (mg/dl) }\end{array}$ & $\begin{array}{l}\text { Mean follow-up post-prandial } \\
\text { blood glucose levels (mg/dl) }\end{array}$ & $\begin{array}{l}\text { Percentage (\%) change in the reduction } \\
\text { of post-prandial blood glucose levels }\end{array}$ \\
\hline Atorvastatin & 178 & 195 & 9.5 \\
Atorvastatin combination & 202 & 213 & 5.4 \\
Rosuvastatin & 111 & 87 & -21.6 \\
Rosuva combination & 183 & 176 & -3.8 \\
\hline
\end{tabular}

Table 12: HbA1c levels of the control group

\begin{tabular}{|c|c|c|c|}
\hline Name of the statin & $\begin{array}{l}\text { Mean baseline HbA1c } \\
\text { levels (mg/dl) }\end{array}$ & $\begin{array}{l}\text { Mean follow-up HbA1c } \\
\text { levels (mg/dl) }\end{array}$ & $\begin{array}{l}\text { Percentage }(\%) \text { change in } \\
\text { reduction of } \mathrm{HbA} 1 \mathrm{c} \text { levels }\end{array}$ \\
\hline Atorvastatin & 7.2 & 8 & 11.1 \\
\hline Rosuvastatin & 5.6 & 5 & -10.7 \\
\hline Rosuva combination & 6.5 & 6.3 & -3 \\
\hline
\end{tabular}


in $\mathrm{HbA} 1 \mathrm{c}$ levels $(-10.7 \%)$ followed by rosuvastatin combination therapy $(-3 \%)$.

Table 13 and Fig. 13: It explains the percentage of triglyceride (TG) levels, of which rosuvastatin combination therapy showed a significant decline in TG levels $(-23.8 \%)$ followed by atorvastatin monotherapy $(-18 \%)$.

Table 14 and Fig. 14: It explains the percentage of HDL levels of which rosuvastatin monotherapy showed a notifiable increment in HDL levels $(23.8 \%)$ followed by rosuvastatin combination therapy $(2.5 \%)$

Table 15 and Fig. 15: It explains the percentage of LDL levels, of which rosuvastatin combination therapy showed a remarkable decrease in LDL levels $(-14.7 \%)$ followed by rosuvastatin monotherapy (9.2\%).

Table 16 and Fig. 16: It explains the percentage of TG levels, of which rosuvastatin combination therapy showed a remarkable decrease in TG levels $(-22.3 \%)$ followed by rosuvastatin monotherapy $(-13.1 \%)$.

Table 17 and Fig. 17: It explains the percentage of HDL levels, of which rosuvastatin monotherapy showed a remarkable increase in HDL levels (38.8\%) followed by rosuvastatin combination therapy (17.1\%).

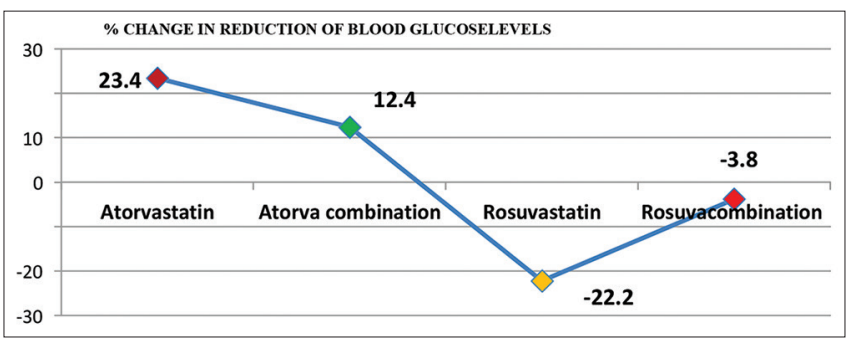

Fig. 10: Fasting blood sugar levels of the control group

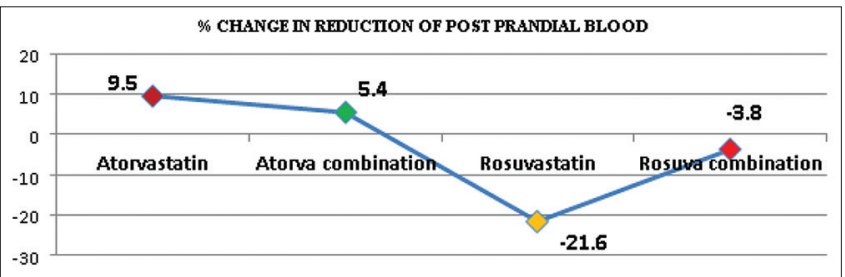

Fig. 11: Post-prandial blood sugar levels of the control group

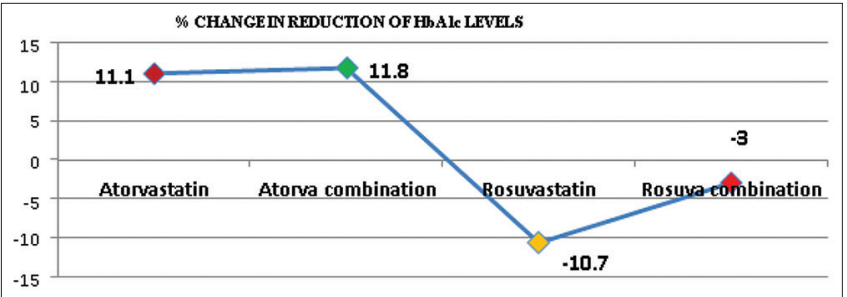

Fig. 12: Hemoglobin A1C levels of the control group

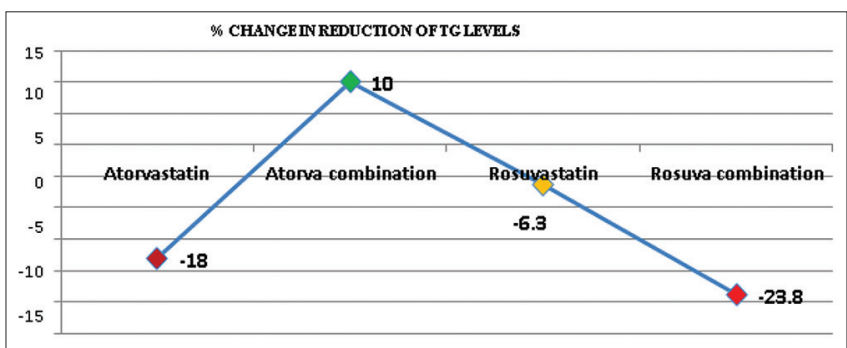

Fig. 13: Triglyceride levels of the treatment group
Table 18 and Fig. 18: It explains the percentage of LDL levels, of which rosuvastatin monotherapy showed a remarkable decrease in LDL levels $(-41.3 \%)$ followed by rosuvastatin combination therapy $(-5.4 \%)$.

Comparison of different parameters in control versus treatment groups using multivariate analysis

\begin{tabular}{lll}
\hline Variables & \multicolumn{2}{l}{ Control vs. treatment } \\
\cline { 2 - 3 } & Z value & p-value \\
\hline Atorvastatin & 0.407 & $0.423^{*}$ \\
Atorva-combination & 0.790 & $0.062^{* *}$ \\
Rosuva statin & 0.765 & $0.076^{* *}$ \\
Rosuva combination & 0.850 & $0.032^{* *}$ \\
\hline
\end{tabular}

*: Significant, ${ }^{* *}$ : Highly significant

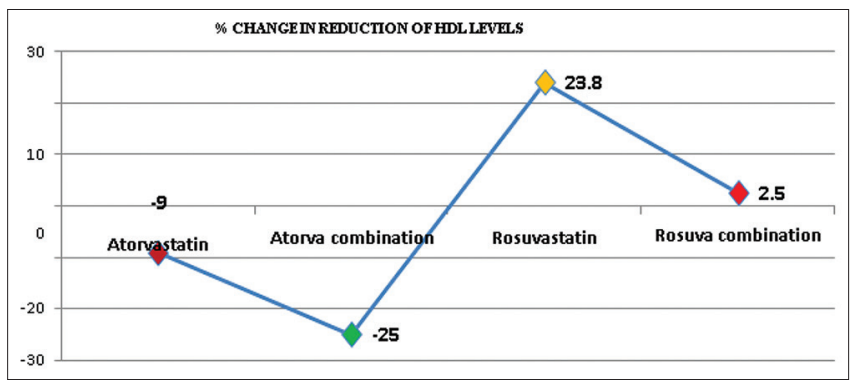

Fig. 14: High-density lipoproteins levels of the treatment group

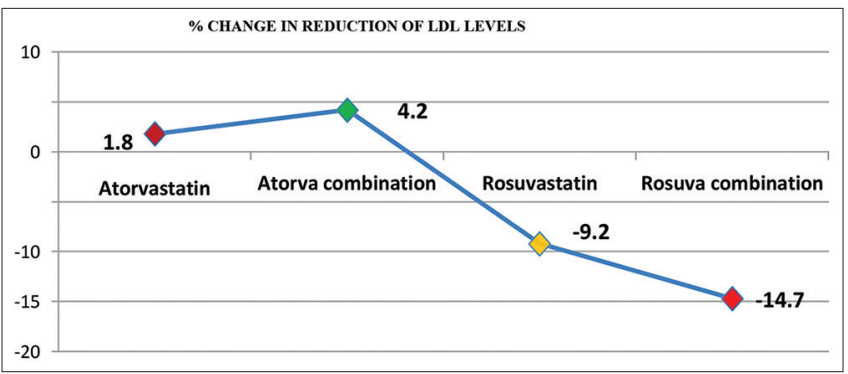

Fig. 15: Low-density lipoprotein levels of the treatment group

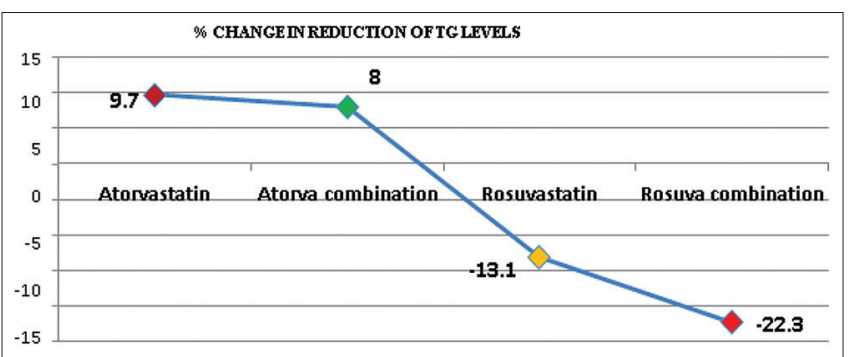

Fig. 16: Triglyceride levels of the control group

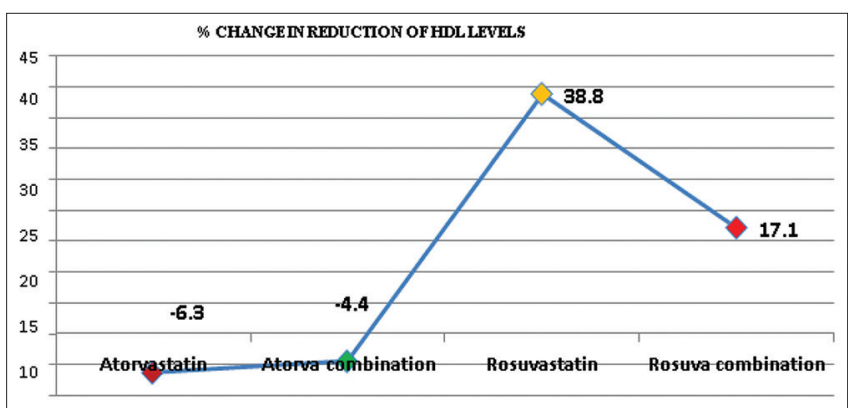

Fig. 17: High-density lipoproteins levels of the control group 
Table 13: Triglyceride levels of the treatment group

\begin{tabular}{llll}
\hline Name of the statin & $\begin{array}{l}\text { Mean baseline TG } \\
\text { levels }(\mathbf{m g} / \mathbf{d l})\end{array}$ & $\begin{array}{l}\text { Mean follow-up TG } \\
\text { levels (mg/d) }\end{array}$ & $\begin{array}{l}\text { Percentage (\%) change in } \\
\text { reduction of TG levels }\end{array}$ \\
\hline Atorvastatin & 234 & 190 & -18 \\
Atorvastatin combination & 210 & 231 & 10 \\
Rosuvastatin & 79 & 176 & -6.3 \\
Rosuva combination & 231 & -23.8 \\
\hline
\end{tabular}

TG: Triglyceride

Table 14: HDL levels of the treatment group

\begin{tabular}{llll}
\hline Name of the statin & $\begin{array}{l}\text { Mean baseline HDL } \\
\text { levels } \mathbf{( m g / d \mathbf { l } )}\end{array}$ & $\begin{array}{l}\text { Mean follow-up HDL } \\
\text { levels (mg/dl) }\end{array}$ & $\begin{array}{l}\text { Percentage (\%) change in } \\
\text { the reduction of HDL levels }\end{array}$ \\
\hline Atorvastatin & 44 & 40 \\
Atorvastatin combination & 39 & 29 \\
Rosuvastatin & 21 & 26 \\
Rosuva combination & 40 & 41 & -9 \\
\hline
\end{tabular}

HDL: High-density lipoproteins

Table 15: LDL levels of the treatment group

\begin{tabular}{llll}
\hline Name of the statin & $\begin{array}{l}\text { Mean baseline LDL } \\
\text { levels } \mathbf{( m g / d )}\end{array}$ & $\begin{array}{l}\text { Mean follow-up LDL } \\
\text { levels } \mathbf{~ ( m g / d ) ~}\end{array}$ & $\begin{array}{l}\text { Percentage (\%) change in } \\
\text { the reduction of LDL levels }\end{array}$ \\
\hline Atorvastatin & 107 & 109 & 1.8 \\
Atorvastatin combination & 95 & 99 & 4.2 \\
Rosuvastatin & 40 & 37 & -9.2 \\
Rosuva combination & 88 & 75 & -14.7 \\
\hline
\end{tabular}

LDL: Low-density lipoprotein

Table 16: TG levels of the control group

\begin{tabular}{llll}
\hline Name of the statin & $\begin{array}{l}\text { Mean baseline TG } \\
\text { levels } \mathbf{( m g / d \mathbf { l } )}\end{array}$ & $\begin{array}{l}\text { Mean follow-up TG } \\
\text { levels }(\mathbf{m g} / \mathbf{d l})\end{array}$ & $\begin{array}{l}\text { Percentage (\%) change in } \\
\text { the reduction of TG levels }\end{array}$ \\
\hline Atorvastatin & 225 & 247 & 9.7 \\
Atorvastatin combination & 236 & 255 & 8 \\
Rosuvastatin & 122 & 106 & -13.1 \\
Rosuva combination & 192 & 149 & -22.3 \\
\hline
\end{tabular}

TG: Triglyceride

Table 17: HDL levels of the control group

\begin{tabular}{llll}
\hline Name of the statin & $\begin{array}{l}\text { Mean baseline HDL } \\
\text { levels } \mathbf{( m g / d )}\end{array}$ & $\begin{array}{l}\text { Mean follow-up HDL } \\
\text { levels (mg/dl) }\end{array}$ & $\begin{array}{l}\text { Percentage (\%) change in the } \\
\text { reduction of HDL levels }\end{array}$ \\
\hline Atorvastatin & 47 & 44 & -6.3 \\
Atorvastatin combination & 45 & 43 & -4.4 \\
Rosuvastatin & 18 & 25 & 38.8 \\
Rosuva combination & 35 & 41 & 17.1 \\
\hline
\end{tabular}

HDL: High-density lipoproteins

Table 18: LDL levels of the control group

\begin{tabular}{llll}
\hline Name of the statin & $\begin{array}{l}\text { Mean baseline LDL } \\
\text { levels (mg/dl) }\end{array}$ & $\begin{array}{l}\text { Mean follow-up LDL } \\
\text { levels (mg/dl) }\end{array}$ & $\begin{array}{l}\text { Percentage (\%) change in the } \\
\text { reduction of LDL levels }\end{array}$ \\
\hline & 116 & 120 & 3.4 \\
Atorvastatin-combination & 96 & 38 & 2 \\
Rosuvastatin & 58 & 87 & -41.3 \\
Rosuva combination & 92 & -5.4 \\
\hline
\end{tabular}

LDL: Low-density lipoprotein

Multivariate analysis has been performed using SPSS version 20. Pearson correlation coefficient between different parameters in control and treated groups was calculated as $\mathrm{Z}$ value at the level of significance $(Z<1)$ and also two-tailed ANOVA performed to calculate $p$-value at the level of significance $(\mathrm{p}<0.5)$.

\section{DISCUSSION}

Despite the importance of the impact of statin therapy for achieving therapeutic goals, there are limited reports on the effect of statin therapy and its associated factors. Education in cholesterol ratio was 


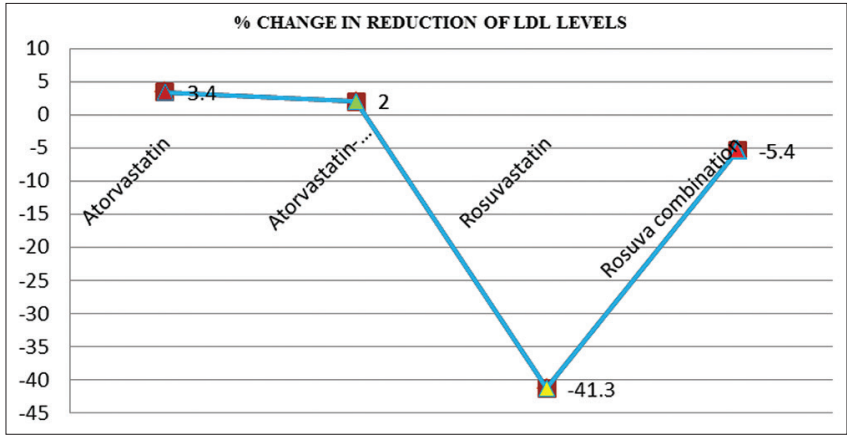

Fig. 18: Low-density lipoprotein levels of the control group

shown to be associated with adherence to treatment and following diet and exercises. Through the questionnaires, the data about a patient's adherence to statins were assessed. Our results revealed that according to the inquiries and obtained data from the case records, three fourth of patients with diabetes were adherent to statins therapy. We conducted a prospective observational study in patients with Type-2 diabetes under treatment with statins. We have collected 450 cases among which 300 cases are patients with DM under statins treatment (considered as a treatment group), 150 cases are patients without DM under statins treatment (considered as a control group). We observed rosuvastatin (10 $\mathrm{mg}$ and $20 \mathrm{mg}$ ) was found to be the most effective statin at reducing FBS, PPBS, and HbA1c levels when compared with rosuvastatin combination, and remarkable increment of these levels was observed with atorvastatin combination followed by atorvastatin $(10 \mathrm{mg}, 20 \mathrm{mg}$, and $40 \mathrm{mg})$. In other words, rosuvastatin at its lowest dose in this study $(10 \mathrm{mg})$ was more effective at reducing FBS, PPBS, and HbA1c levels than rosuvastatin combination and significant increment of these levels was observed with atorvastatin combination followed by atorvastatin $(10 \mathrm{mg}, 20 \mathrm{mg}$, and $40 \mathrm{mg}$ ) in both treatment group as well as a control group. On applying statistics (SPSS version 20. Pearson correlation coefficient), we found that our study was significant.

\section{CONCLUSION}

From this study, we concluded that there is a significant rise in blood glucose levels (both FBS and PPBS) and also HbA1c levels (glycated hemoglobin) due to the usage of statins for a longer duration. Among the various types of statins, the most commonly used statins are atorvastatin monotherapy, atorvastatin combination therapy followed by rosuvastatin. Rosuvastatin combination therapy and particular raise are seen more frequently with atorvastatin combination therapy and atorvastatin monotherapy and less commonly seen with rosuvastatin combination therapy and rosuvastatin monotherapy.
Finally, we conclude that statins use showing a remarkable increase in blood glucose levels (both FBS and PPBS) and also HbA1c levels (glycated hemoglobin). The need for drug utilization evaluation is necessary to improve the quality of life by avoiding unnecessary usage of statins to prevent serious adverse effects. The pharmacist is the key person for better management of therapy based on the stage and condition of the patient. On applying statistics (SPSS version 20. Pearson correlation coefficient), we found that our study was significant.

\section{CONFLICTS INTEREST}

In this study would not interest any conflicts.

\section{AUTHORS' CONTRIBUTIONS}

We would like to thank all contributors for making this paper.

\section{ACKNOWLEDGMENT}

Genuinely acknowledge my gratefulness to Dr. Sk. Abdul Rehaman, Professor, Principal, Nirmala College of Pharmacy, Mangalagiri, India and for his valuable guidance, constant encouragement, support, and inspiration throughout research work.

\section{REFERENCES}

1. Shargel L, Mutnick AH, Swanson LN. Comprehensive Pharmacy Review. $8^{\text {th }}$ ed. United States: Lippincott, Williams and Wilkins Publishers; 2013.

2. Tripathi KD. Essentials of Medical Pharmacology. $7^{\text {th }}$ ed. Tamil Nadu: Jaypee Publishers; 2013

3. Dipiro JT, Talbert R, Yee G, Matzke G, Wells B, Posey LM. Pharmacotherapy-a Pathophysiologic Approach. $10^{\text {th }}$ ed. United States: McGraw-Hill Education Publishers; 2017.

4. Krauss RM. Lipids and lipoproteins in patients with Type 2 diabetes. Diabetes Care 2004;27:1496-504

5. Vani C, Narayana BL, Prashanthi P, Karthik B. Analyzing the impact of statins use in Type-2 diabetes mellitus patients. IOSR J Pharm Biol Sci 2018;13:45-53.

6. Baum T, Yap SP, Karampinos DC, Nardo L, Kuo D, Burghardt AJ, et al. Does vertebral bone marrow fat content correlate with abdominal adipose tissue, lumbar spine bone mineral density, and blood biomarkers in women with Type 2 diabetes mellitus? J Magn Reson Imaging 2012;35:117-24.

7. Miettinen TA. Diurnal variation of cholesterol precursors squalene and methyl sterols in human plasma lipoproteins. J Lipid Res 1982;23:466-73.

8. Baigent C, Blackwell L, Emberson J, Holland LE, Reith C, Bhala N, et al. Efficacy and safety of more intensive lowering of LDL cholesterol: A meta-analysis of data from 170,000 participants in 26 randomised trials. Lancet 2010;376:1670-81.

9. Saito Y, Yoshida S, Nakaya N, Hata Y, Goto Y. Comparison between morning and evening doses of simvastatin in hyperlipidemic subjects. A double-blind comparative study. Arterioscler Thromb 1991;11:816-26.

10. Wallace A, Chinn D, Rubin G. Taking simvastatin in the morning compared within the evening: Randomised controlled trial. BMJ 2003;327:788. 